\title{
Optimization of Osmotic Dehydration of Chestnut (Castanea sativa Mill.) Slices Using Response Surface Methodology
}

\author{
Teresa Delgado ${ }^{\mathrm{a}, \mathrm{b}}$, Bruna Paim ${ }^{\mathrm{c}}$, José Alberto Pereira ${ }^{\mathrm{a}}$, Susana Casal $^{\mathrm{b}}$, And \\ Elsa Ramalhosa ${ }^{a^{*}}$ \\ ${ }^{\text {a }}$ CIMO - Mountain Research Center, School of Agriculture, Polytechnic Institute of Bragança, Campus de St ${ }^{\text {a }}$ \\ Apolónia, 5300-253 Bragança, Portugal \\ b LAQV@REQUIMTE, Laboratório de Bromatologia e Hidrologia, Faculdade de Farmácia da Universidade do \\ Porto, Rua de Jorge Viterbo Ferreira, no 228, 4050-313 Porto, Portugal \\ ${ }^{\mathrm{c}}$ Instituto Federal de Educação, Ciência e Tecnologia Farroupilha Alegrete, Campus Alegrete, Alegrete, Brasil \\ ${ }^{*}$ Corresponding author \\ elsa@ipb.pt \\ TEL: $+351-273303308$ \\ FAX: +351-273325405
}

Received: 9 February 2017; Published online: 18 April 2018

\begin{abstract}
Osmotic dehydration of chestnut slices in sucrose was optimized for the first time by Response Surface Methodology (RSM). Experiments were planned according to a three-factor central composite design ( $\alpha=1.68$ ), studying the influence of sucrose concentration, temperature and time, on the following parameters: volume ratio, water activity, color variation, weight reduction, solids gain, water loss and normalized moisture content, as well as total moisture, ash and fat contents.

The experimental data was adequately fitted into second-order polynomial models with coefficients of determination $\left(\mathrm{R}^{2}\right)$ from 0.716 to 0.976 , adjusted- $\mathrm{R}^{2}$ values from 0.460 to 0.954 , and non-significant lacks of fit. The optimal osmotic dehydration process conditions for maximum water loss and minimum solids gain and color variation were determined by the "Response Optimizer" option: $83 \%$ sucrose concentration, $20{ }^{\circ} \mathrm{C}$ and 9.2 hours. Thus, the best operational conditions corresponded to high sugar concentration and low temperature, improving energy saving and decreasing the process costs.
\end{abstract}

Keywords: Chestnut; Castanea sativa Miller; Osmotic Dehydration; Response Surface Methodology; Physicochemical properties

\section{Introduction}

Chestnut production is of great economic importance for some countries. In 2012, the main world producer was China, representing about $82.5 \%$ of the total production, followed by Europe, with 6.4\% (Food and Agriculture Organization of the United Nations, 2014). Portugal accounts for about $15 \%$ of the European production (Food and Agriculture Organization of the United Nations, 2014), with the North area, mainly Trás-
os-Montes region, contributing to $80.5 \%$ of the national production and representing $87.4 \%$ of chestnut national production area (30586 ha) (Instituto Nacional de Estatística, 2014).

Being a seasonal product, some problems may arise during chestnuts' storage, compromising its availability and quality throughout the year. One way to mitigate this problem is to use different post-harvest technologies such as low temperature storage or convection drying. However, a promising technology to preserve perishable 


\section{Nomenclature}

RSM Response Surface Methodology

OD Osmotic dehydration

$W R \quad$ Weight Reduction $\left(\mathrm{g} \mathrm{g}^{-1}\right.$ fresh chestnut)

$S G \quad$ Solids Gain ( $\mathrm{g} \mathrm{g}^{-1}$ fresh chestnut)

$W L \quad$ Water Loss ( $\mathrm{g} \mathrm{g}^{-1}$ fresh chestnut)

NMC Normalized Moisture Content

$a_{w} \quad$ Water activity

$M_{0} \quad$ Sample mass before osmotic dehydration $(\mathrm{g})$
M Sample mass after osmotic dehydration (g)

$m_{0} \quad$ Initial mass of the solids in chestnut sample $(\mathrm{g})$

$m \quad$ Mass of the solids in chestnut sample after osmotic dehydration (g)

$W, L, t$ Axial dimensions (Width, Length and thickness, respectively $(\mathrm{mm}))$

$L^{*}, a^{*}, b^{*}$ Color parameters (CIE $\left.L a b\right)$

$\mathrm{X} \quad$ Moisture ratio

CCD Central Composite Design items and make them available to distant regions of a production area throughout the year is osmotic dehydration (OD) which is a simple and a low cost method (Rastogi, Raghavarao, Niranjan, \& Knorr, 2002; Shi \& Le Maguer, 2002). Furthermore, with this OD technology an interesting chestnut snack may be produced. As chestnut is naturally gluten-free, snacks of this nut may be a good option for celiac patients.

Osmotic dehydration occurs by immersion of the food in osmotic solutions. During this process, the cellular structure of the food allows water loss, while a gain of solute occurs simultaneously (Rastogi, Raghavarao, \& Niranjan, 1997). Both mass flows are affected by diverse factors, including the nature of the food and its geometry, the composition and concentration of the osmotic solution, and several methodological parameters such as temperature, contact time and agitation (Kaymak-Ertekin \& Sultanoglu, 2000; Singh, Kumar, \& Gupta, 2007; Tonon, Baroni, \& Hubinger, 2007).

Diverse statistical and mathematical techniques have been applied to optimize and improve the development of these processes, combining and analyzing the role of different factors such as temperature, solute concentration and time, while minimizing analyses' error and the amount of necessary experiments. Response Surface
Methodology (RSM) is one of these techniques, aiming to optimize response-variables of interest by studying the influence of a defined number of independent variables. Besides having the advantage of analyzing the effects of independent variables, this methodology generates a mathematical model that describes the chemical or biochemical processes under study (Anjum, Tasadduq, \& AlSultan, 1997). In particular, RSM has been applied to osmotic dehydration studies of some fruits and vegetables, including apples (Azarpazhooh \& Ramaswamy, 2012), bananas (Atares, Gallagher, \& Oliveira, 2011), carrots (Changrue, Orsat, Raghavan, \& Lyew, 2008), cherry tomatoes (Derossi, Severini, Del Mastro, \& De Pilli, 2015), figs (Vasconcelos, Andrade, Maciel, Guerra, \& Vasconcelos, 2012), green peppers (Ozdemir, Ozen, Dock, \& Floros, 2008), kiwi (Cao, Zhang, Mujumdar, Du, \& Sun, 2006), peaches (Yadav, Yadav, \& Jatain, 2012), plums (Koocheki \& Azarpazhooh, 2010) and strawberries (Changrue et al., 2008). Generally, three factors are studied, namely, temperature, time and concentration of the osmotic solution (Azarpazhooh \& Ramaswamy, 2012; Cao et al., 2006; Changrue et al., 2008; Koocheki \& Azarpazhooh, 2010; Vasconcelos et al., 2012; Yadav et al., 2012).

Regarding chestnut, most studies of OD have 
been focused on whole fruits of Spanish chestnut varieties, and primarily on diverse osmotic agents and temperatures (Chenlo, Moreira, FernándezHerrero, \& Vázquez, 2006b, 2006a, 2007; Moreira, Chenlo, Chaguri, \& Oliveira, 2007; Moreira, Chenlo, Chaguri, \& Fernandes, 2008; Moreira, Chenlo, Chaguri, \& Vazquez, 2011; Moreira, Chenlo, Chaguri, \& Mayor, 2011). The osmotic agents studied included sodium chloride (17 to $26.5 \%$ ), glucose and sucrose (40 to $60 \%$ ) at different concentrations and submitted to several temperatures in the range of 25 and $65{ }^{\circ} \mathrm{C}$.

Nevertheless, none of these studies performed the optimization of the OD process taking into account several factors and responses simultaneously. Thus, the aims of our work were: i) to evaluate by RSM the role of the three main parameters, temperature, time and concentration of the osmotic solution (sucrose), in affecting some physicochemical properties of chestnut slices; and ii) to optimize these parameters for the industrial production of an interesting chestnut based snack in the near future. Sucrose was the first osmotic agent to be tested by RSM because it is more common to use this compound in OD processes of fruits than sodium chloride that can induce high blood pressure (Appel et al., 2012). Furthermore, sucrose is also cheaper than glucose.

\section{Materials and Methods}

\section{$2.1 \quad$ Plant material}

Castanea sativa Miller (European chestnut) fruits, variety Longal, were acquired in Bragança (NE Portugal) in November 2013, and stored in cold chambers $\left(4 \pm 1{ }^{\circ} \mathrm{C}\right)$ until the osmotic dehydration experiments were performed. Before doing these experiments, chestnuts were carefully unshelled and sliced (approximately $4-6 \mathrm{~mm}$ of thickness).

\subsection{Osmotic Dehydration (OD)}

The osmotic solutions were prepared with foodgrade sucrose and potable water. The OD experiments were carried out in $1 \mathrm{~L}$ beakers. For each condition, $70 \mathrm{~g}$ of fresh sliced chestnuts were added to $700 \mathrm{~mL}$ of sugar solution and mixed with a magnetic stirrer at $310 \mathrm{rpm}$ in a temperature controlled water bath. At specific times, the dehydrated chestnut slices were removed from the solution, drained, and gently cleaned with absorbent paper to remove any sugar solution in excess. For each condition, the assays were performed in duplicate.

In order to adequately follow the OD kinetics, several parameters were analyzed, namely weight reduction $(W R)$, solids gain $(S G)$, water loss $(W L)$ and normalized moisture content $(N M C)$. These were determined according to the following equations (Eq. 1 to 4) (Lerici, Pinnavaia, Rosa, \& Bartolucci, 1985):

$$
\begin{gathered}
W R=\frac{M_{0}-M}{M_{0}} \\
S G=\frac{m-m_{0}}{M_{0}} \\
W L=W R+S G \\
N M C=\frac{1-\frac{m}{M}}{1-\frac{m_{0}}{M_{0}}}=\frac{X}{X_{0}}
\end{gathered}
$$

where $M_{0}$ and $M$ represents the total mass of sample before and after OD, respectively; $m_{0}$ and $m$ are the mass of the solids before and after OD, respectively; and $X_{0}$ and $X$ correspond to the moisture contents of the samples before and after the OD treatment, respectively.

\subsection{Physicochemical characterization}

\section{Volume}

The three axial dimensions (Width, $W$; Length, $L$; and thickness, $h$ ) of all chestnut slices were measured using a digital caliper, before and after the OD experiments. Volume was calculated by the following equation:

$$
V=\text { Area of the elipse } \times h=\pi \times \frac{W}{2} \times \frac{L}{2} \times h
$$

The volume was calculated by considering the dimensions before $\left(V_{0}\right)$ and after $(V) \mathrm{OD}$, enabling the calculation of the volume ratio $\left(\frac{V}{V_{0}}\right)$. 


\section{Color}

Color analyses were carried out on chestnut slices before and after being subjected to OD. A Minolta CR-400 colorimeter was used, in CIE $L a b$ color space, through the coordinates $L^{*}, a^{*}$ and $b^{*}$, using the Spectra Magic Nx software (version CM-S100W 2.03.0006, Konica Minolta Company, Osaka, Japan), as already described in previous work (Delgado, Pereira, Baptista, Casal, \& Ramalhosa, 2014).

In order to analyze the color changes due to the OD process, the total color difference $\left(\Delta E^{*}\right)$ was calculated according to:

$$
\Delta E^{*}=\sqrt{\left(\Delta L^{*}\right)^{2}+\left(\Delta a^{*}\right)^{2}+\left(\Delta b^{*}\right)^{2}}
$$

All color determinations were made on 20 slices, before (the color of fresh chestnuts was considered as reference) and after the OD process, each time in duplicate.

\subsection{Water activity $\left(\mathrm{a}_{w}\right)$, moisture, ash and crude fat contents}

Water activity was determined by means of a LabSwift- $\mathrm{a}_{w}$ instrument (Novasina AG, Lachen, Switzerland). The instrument was calibrated with three water activity standards, namely $11 \%$ $\left(\mathrm{a}_{w}=0.112\right), 58 \%\left(\mathrm{a}_{w}=0.587\right)$ and $84 \%\left(\mathrm{a}_{w}\right.$ $=0.845)$.

Moisture, ash and crude fat contents were determined using standard procedures (Association of Official Analytical Chemists, 1995) in duplicate on samples of each osmotic dehydration assays $(n=4)$. All reagents were of analytical grade and purchased from Sigma-Aldrich Chemical Co. (St Louis, MO, USA). Crude fat was determined on $5 \mathrm{~g}$ of sample, using petroleum ether for $24 \mathrm{~h}$ in a Soxhlet apparatus (P Selecta, Abrera, Barcelona). Moisture was determined on $5 \mathrm{~g}$ of sample at $105{ }^{\circ} \mathrm{C}$ in an oven (Memmert UNB 500, Schwabach, Germany), until constant weight, while total ash was obtained by incineration at $550{ }^{\circ} \mathrm{C}$ (Lenton Thermal Designs Ltd, Hope Valley, United Kingdom). The ash and crude fat contents were expressed on $\mathrm{g} 100 \mathrm{~g}^{-1}$ dry matter.

\subsection{Experimental design and statistical analysis}

In order to determine the effect of selected operational parameters in the above mentioned chestnut properties, as well as to establish the best conditions to perform OD of chestnut slices, the Response Surface Methodology (RSM) was used through Minitab ${ }^{\circledR}$ software (USA). A one block with an $\alpha$-value equal to 1.68 and a central composite design (CCD) was constructed to investigate the influence of the following three independent factors: sucrose concentration, temperature and time. The response variables were $a_{w}, \frac{V}{V_{0}}$, $\Delta E^{*}, W R, S G, W L, N M C$, moisture, ash and crude fat contents. Each variable was coded at five levels: $-1.68,-1,0,+1$ and +1.68 . The correspondence between coded and uncoded variables is indicated in Table 1. Each point of the CCD was carried out in duplicate.

The relationship found between the dependent variables $\left(a_{w}, \frac{V}{V_{0}}, \Delta E^{*}, W R, S G, W L, N M C\right.$, moisture, total ash and crude fat contents) and the operational variables was established by the following second order polynomial model:

$$
Y=\beta_{0}+\sum_{i=1}^{k} \beta_{i} X_{i}+\sum_{i=1}^{k} \beta_{i i} X_{i}^{2}+\sum_{i>j}^{k} \beta_{i j} X_{i} X_{j}
$$

where $Y$ is the predicted dependent variable; $\beta_{0}$ is a constant that fixes the response at the central point of the experiment (constant); $\beta_{i}$ are the regression coefficients for the linear effect terms; $\beta_{i j}$ are the quadratic effect terms; $\beta_{i i}$ are the interaction effect terms of variables $i$ and $j ; X_{i}$ and $X_{j}$ are independent variables $\left(X_{1}-\right.$ sucrose concentration; $X_{2}$ - temperature; $X_{3}$ - time); and $k$ the total number of independent factors $(k=3)$. Twenty experiments, with six replications in the central point (Experiments 1, 5, 14, 15, 19 and 20 ), were performed (Table 2). In order to limit the influence of systematic errors, the sequence of the experiments was randomized. The experiments performed in the central point allowed an estimate of experimental error, whereas the other experiments allowed the calculation of the regression coefficients of the model. The adequacy of the models was assessed through the coefficient of determination $\left(\mathrm{R}^{2}\right)$, the adjusted- $\mathrm{R}^{2}$ $\left(\operatorname{adj}-\mathrm{R}^{2}\right)$ and the analysis of variance (ANOVA). 
Table 1: Independent variables and their coded and uncoded values for optimization

\begin{tabular}{cccc}
\hline \multirow{2}{*}{ Coded value } & $\begin{array}{c}\text { Sucrose concentration } \\
(\boldsymbol{\%}, \mathbf{w} / \mathbf{v})\end{array}$ & $\begin{array}{c}\text { Temperature } \\
\left({ }^{\circ} \mathbf{C}\right)\end{array}$ & $\begin{array}{c}\text { Time } \\
(\mathbf{h})\end{array}$ \\
\hline-1.68 & 53 & $\boldsymbol{X}_{2}$ & $\boldsymbol{X}_{3}$ \\
\hline-1 & 60 & 20 & 0.8 \\
0 & 70 & 30 & 2.5 \\
1 & 80 & 45 & 5.0 \\
1.68 & 87 & 60 & 7.5 \\
\hline
\end{tabular}

Furthermore, the lack of fit of the models was used to check the quality of second-order polynomial models. If the p-value of the lack of fit is less than 0.05 , evidence exists that the model does not accurately fit the data.

In order to obtain useful information about the behavior of the system within the experimental design, response surface plots were generated for different interactions of any two independent variables, while holding the value of a third variable constant. Furthermore, at the end an optimization of the osmotic dehydration process was performed by using the "Response Optimizer" option of Minitab ${ }^{\circledR}$ software, in order to define the levels of the independent variables that would give maximum water loss and the lowest solids gain and $\Delta E^{*}$ (these response-variables are very important to achieve a product that will be well accepted by consumers). The optimization procedure picks several starting points from which to begin searching for the optimal factor settings, being displayed as the global solution, which corresponds to the "best" combination of factor settings for achieving the desired responses. In more detail, the optimization is accomplished by:

- obtaining the individual desirability for each response. The individual desirability will be closer to one, if the response is closer to the defined target (in the present work, our goal was to maximize water loss and minimize solids gain and $\left.\Delta E^{*}\right)$;

- combining the individual desirabilities to obtain the combined or composite desirability. This measure is the weighted geometric mean of the individual desirabilities for the responses. In the present work, all individual desirabilities were equally important, so they had the same weight. In the present work the weight used was 1 (we placed equal emphasis on the target and the bounds). The composite desirability has a range of zero to one. One represents the ideal case, while zero indicates that one or more responses are not inside their acceptable limits;

- at the end, Minitab employs a reduced gradient algorithm with multiple starting points that maximizes the composite desirability to determine the numerical optimal solution. At the end, the optimal input variable settings were tested to confirm if the optimal response was observed.

\section{Results and Discussion}

The coefficients of the second-order response surface models relating response variables with sugar concentration, temperature and time are described in Table 3. For the volume ratio and $\mathrm{a}_{w}$, the model results are not shown because the p-value of the lack of fit was lower than 0.05 (0.001 and 0.003, respectively), suggesting that the models developed did not represent accurately the observed results. A good fit between the experimental data and the predicted values by the model is obtained when high $R^{2}$ and adj- $R^{2}$ (near 1 ) are achieved together with a p-value for the lack of fit higher than 0.05 , indicating that the variation between samples was only due to the factors selected for the model and 
the pure error (Minitab ${ }^{\circledR}$ software). Nevertheless, $\frac{V}{V_{0}}$ varied between 0.841 and 1.39 (Table 2) showing that in some situations chestnuts (slices) submitted to OD may shrink or increase volume due to solution absorption. Concerning $\mathrm{a}_{w}$ (Table 2), this parameter varied between 0.849 and 0.935 , a range that is normally encountered for dried foods or with high concentrations of solutes (Pereda et al., 2005; Moreira, Chenlo, Torres, \& Vázquez, 2007).

\subsection{Color variation $\left(\Delta E^{*}\right)$}

Values of color variation predicted by the mathematical model were similar to the experimental data (Table 2), yielding a good fit with a $\mathrm{R}^{2}$ of 0.976 and an adj- $\mathrm{R}^{2}$ of 0.954 (Table 3 ), meaning that the experimental data may be predicted with great accuracy. Moreover, the model was good because the lack of fit was non-significant $(p=0.717)$. Concerning the linear model coefficients, temperature and time were found to be significant model terms on color variation of chestnut slices, whereas the sucrose concentration was not a significant model term. This can be a direct consequence of Maillard reactions taking place when temperature and time increase. Regarding the quadratic terms, the temperature was the only parameter that had a significant effect $(p<0.05)$. The results also showed that the interaction between temperature and time was significant for $\Delta E^{*}$, yielding the following recalculated model taking into account only the significant terms:

$\Delta E^{*}=10.2+4.49 X_{2}+2.02 X_{3}+1.27 X_{2}^{2}+0.866 X_{2} X_{3}$

Furthermore, temperature had a higher effect on $\Delta E^{*}$ than time due to its higher linear coefficient (4.49 versus 2.02$)$. In fact, as shown in Table 2 , the maximum of the color variation was 21.7 at experiment 13 performed at the highest temperature $\left(70{ }^{\circ} \mathrm{C}\right)$. Fig. 1 shows the effect of temperature and time on chestnut slices color variation for a sucrose concentration of $70 \%$. At low temperatures, time had little effect on color variation, which remained quite low. On contrary, the highest variation in $\Delta E^{*}$ occurred when the highest temperature and time were applied. These results showed that, in some situa- tions, an OD process may change chestnut slices color, with $\Delta E^{*}$ values higher than 12 , an indicative value referred to by Cecchini, Contini, Massantini, Monarca, and Moscetti (2011). Color variation might be a negative point because color is one of the most important parameters for consumers' acceptance (Andrés-Bello, BarretoPalacios, García-Segovia, Mir-Bel, \& MartínezMonzó, 2013). These color changes should be mostly due to non-enzymatic browning reactions, namely Maillard and caramelization reactions that are favored by high temperatures (Ajandouz, Desseaux, Tazi, \& Puigserver, 2008). On the other hand, enzymatic browning, due to polyphenoloxidase activity, might be difficult to develop due to the high ionic strength of the medium.

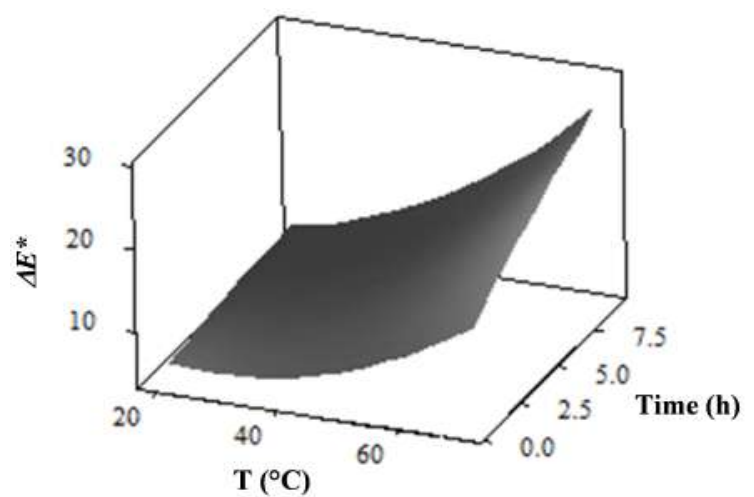

Figure 1: Response Surface plot for $\Delta E^{*}$ as a function of $\mathrm{T}\left({ }^{\circ} \mathrm{C}\right)$ and time $(\mathrm{h})$ at sucrose concentration of $70 \%$

\subsection{Moisture content}

By analyzing Table 2, the values of moisture content predicted by the model were also in good agreement with the experimental data, yielding a good $R^{2}(0.872)$, an adj- $R^{2}$ of 0.756 and a nonsignificant lack of fit $(\mathrm{p}=0.094)$ (Table 3). The minimum and maximum moisture contents on osmotic dehydrated product were 11.4 and $36.3 \mathrm{~g}$ of water $100 \mathrm{~g}^{-1}$, obtained with a sugar concentration of $80 \%(\mathrm{w} / \mathrm{v}), 60{ }^{\circ} \mathrm{C}$ and $7.5 \mathrm{~h}$, and $60 \%$ of sucrose, $30{ }^{\circ} \mathrm{C}$ and $2.5 \mathrm{~h}$, respectively. The 
58 $\mid$ Delgado et al.

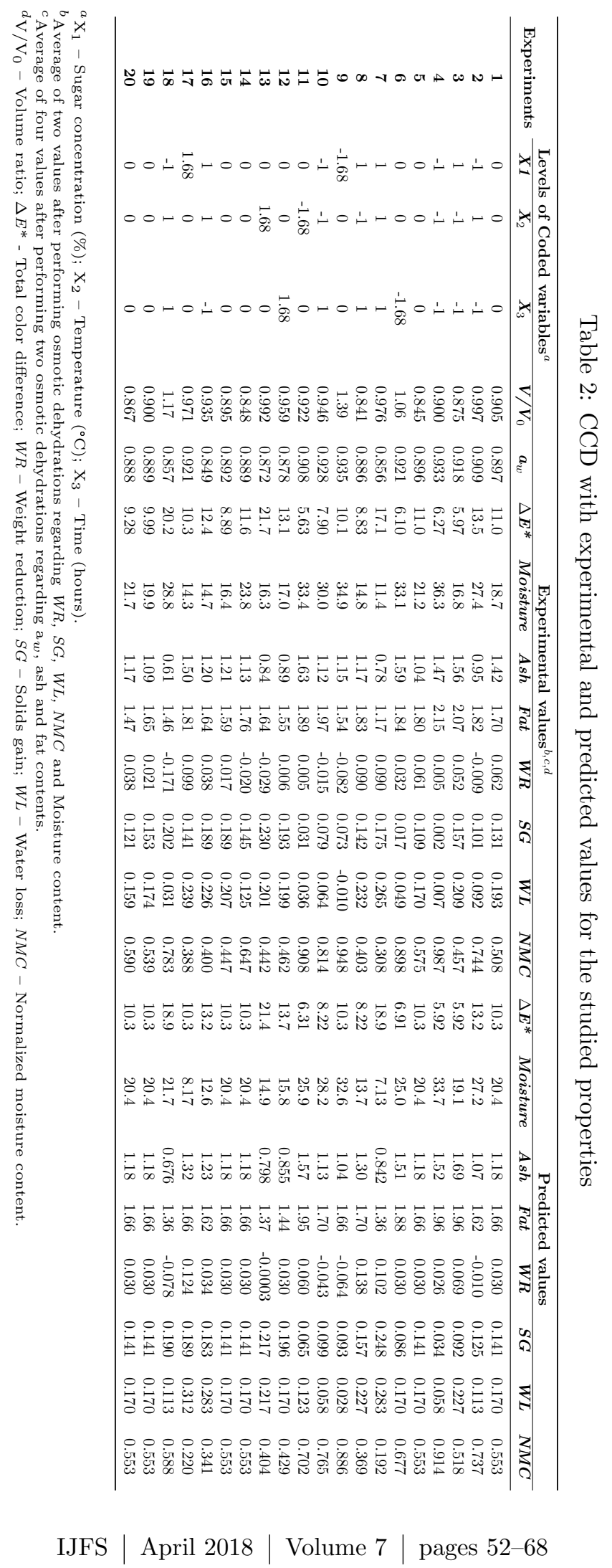


Application of Response Surface Methodology to osmotic dehydration of chestnuts $\mid 59$

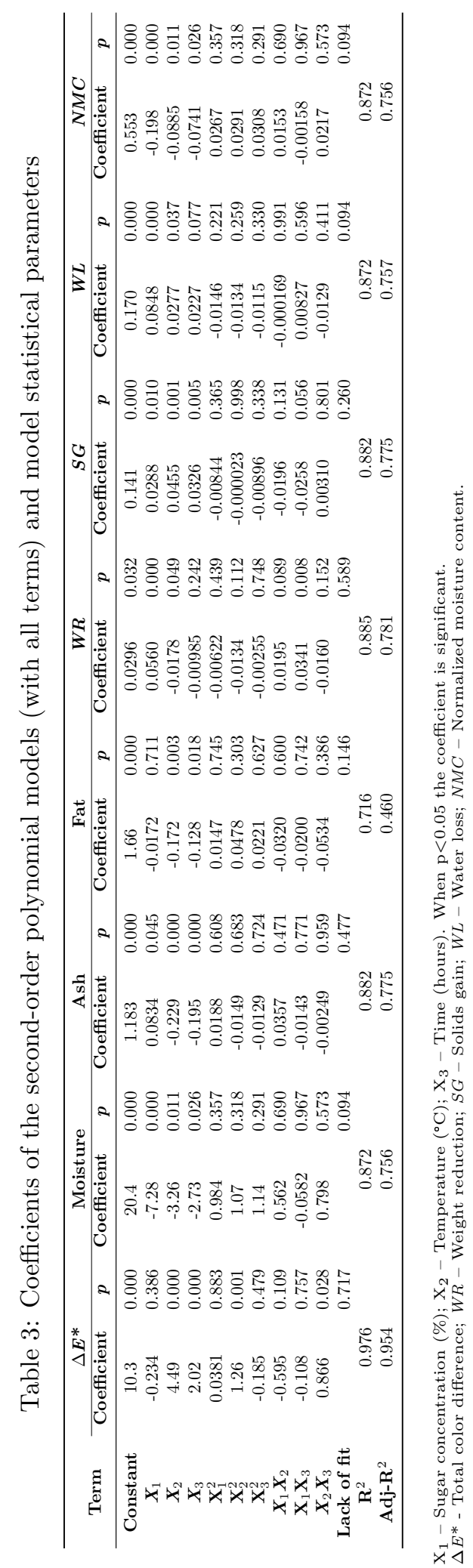

IJFS | April 2018 | Volume $7 \mid$ pages 52-68 
$60 \mid$ Delgado et al.

only significant terms of the model were the linear ones of all factors, namely sucrose concentration, temperature and time. Considering these significant terms, the recalculated model was as follows:

Moisture content $=20.5-7.28 X_{1}-3.26 X_{2}-2.73 X_{3}$

Our results showed that temperature and time had a significant negative effect on moisture content (Fig. 2A). Indeed, these are the main determinants on any drying procedure, being in agreement with Noshad, Mohebbi, Shahidi, and Mortazavi (2012), who reported that an increase of temperature and time promoted a decrease of moisture content in quince. Chenlo et al. (2007) also observed that an increase in the temperature made the dehydration of chestnuts more intense, reaching lower values of moisture content. Furthermore, sucrose concentration also had an important role on moisture content (Fig. 2B), with the high sucrose concentrations yielding the lowest moisture contents. Indeed, sucrose concentration had a higher role than temperature and time, as observed by the highest coefficient of the former $(-7.28$ versus -3.26 and -2.73$)$; however, as the temperature increased (Fig. 2B), moisture content also decreased slightly.

\subsection{Ash content}

The total ash values varied between 0.61 and 1.63 g $100 \mathrm{~g}^{-1}$ of dry matter (Table 2). The predicted values were in agreement with experimental data, yielding a good $\mathrm{R}^{2}(0.882)$, an adj- $\mathrm{R}^{2}$ of 0.775 and a non-significant lack of fit $(p=0.477)$. Again, just the linear terms were significant, yielding the following recalculated model:

Ash content $=1.176+0.0834 X_{1}-0.229 X_{2}-0.195 X_{3}$

Due to the highest absolute values of the coefficients, temperature and time had a higher effect on ash content than sucrose concentration. By analyzing Fig. 2C, we can observe an inverse behavior between ash content and temperature, with the same being verified with time. So, the highest ash content was found at the lowest temperature and time. When comparing the osmotically treated samples (0.61 to $1.63 \mathrm{~g}$ ash $100 \mathrm{~g}^{-1}$ of dry matter) with fresh chestnuts (1.76 g ash $100 \mathrm{~g}^{-1}$ of dry matter), the ash content decreased after the osmotic treatment. This could be due to the diffusion of sucrose to the interior of chestnut or to the output of water from the fruit to the osmotic medium, increasing the dry matter. Furthermore, other possible explanations are as follows: the removal of the shell and pellicle when slicing chestnuts may greatly increase the mass transfer rate of minerals due to the disappearance of adhesive substances and other components in the endocarp that protect the fruit (Moreira, Chenlo, Chaguri, \& Oliveira, 2007) and can also be due to the high osmotic pressure at high sucrose concentrations that may break the cellular walls (Sacchetti, Gianotti, \& Dalla Rosa, 2001), promoting the transfer of some minerals to the osmotic medium.

\subsection{Crude Fat}

The crude fat of chestnut slices contents varied

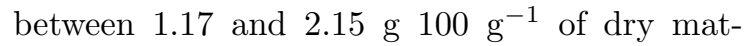
ter (Table 2). A reasonable $\mathrm{R}^{2}$ of 0.716 and an $\operatorname{adj}-R^{2}$ of 0.460 were obtained, showing that this model can reasonably predict the experimental data. As desired, the lack of fit was not significant $(p=0.146)$ (Table 3). Only temperature and time were significant factors, yielding the following recalculated model:

$$
\text { Fat content }=1.72-0.172 X_{2}-0.128 X_{3}
$$

By the analysis of the response surface plot (Fig. 2D), we can predict that crude fat decreases as temperature and time increase. This decrease on fat content could be related with the output of fat to the osmotic medium due to the breakage of cell walls due to the high osmotic pressure (Sacchetti et al., 2001) and/or high temperatures and time. Diffusion of sucrose to the interior of chestnut or the output of water from the fruit to the osmotic medium might also have increased the dry matter, decreasing the fat content in dry basis. In fact, all OD products presented lower crude fat contents than fresh chestnut (3.3\%, dry basis), supporting the hypotheses described above. 

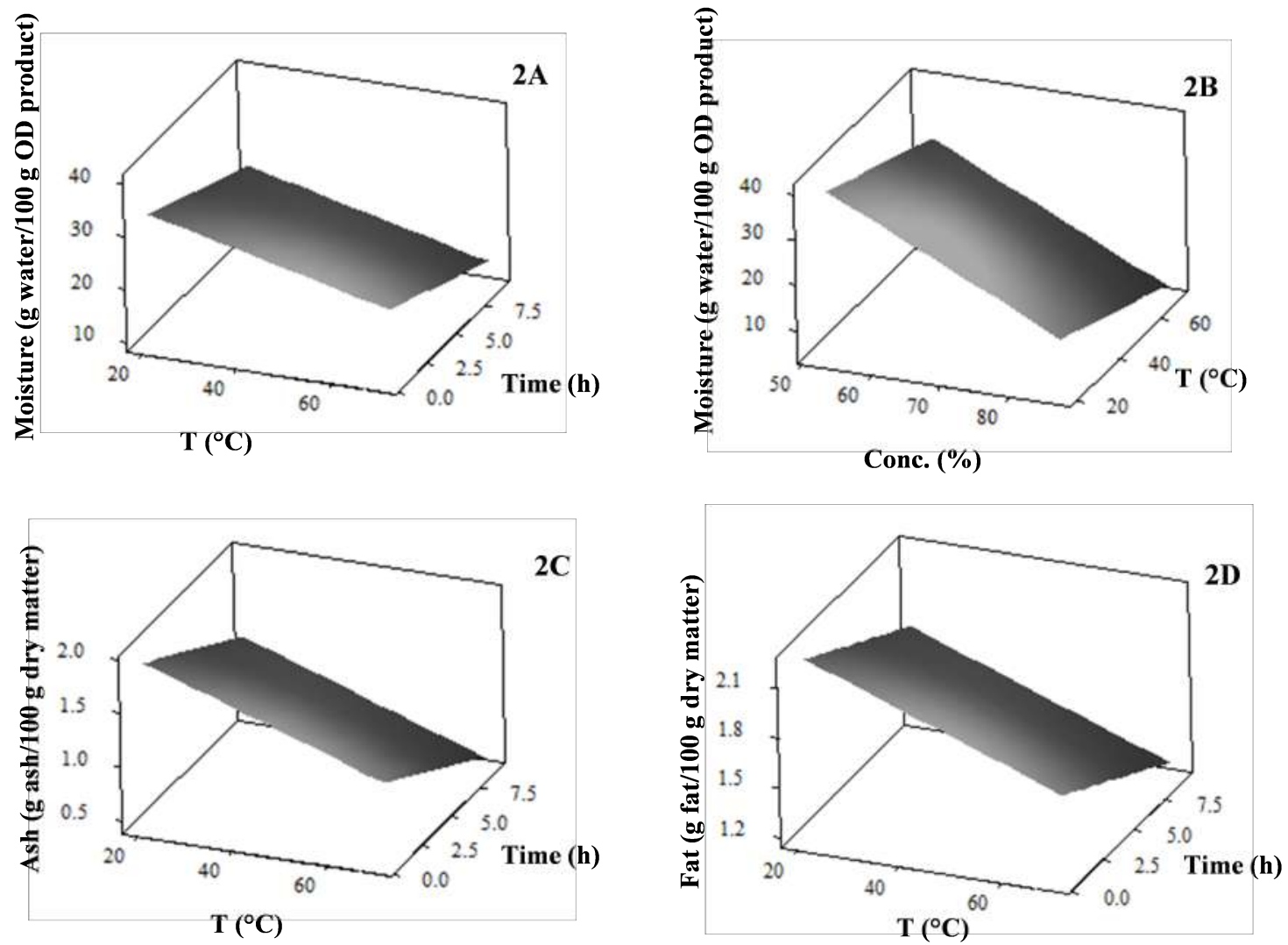

Figure 2: Response Surface plots: (A) Moisture content as a function of $\mathrm{T}\left({ }^{\circ} \mathrm{C}\right)$ and time $(\mathrm{h})$ at sucrose concentration of $70 \%$; (B) Moisture content as a function of sucrose conc. $(\%)$ and $\mathrm{T}\left({ }^{\circ} \mathrm{C}\right)$ at a contact time of 5.0 hours; (C) Ash content as a function of $\mathrm{T}\left({ }^{\circ} \mathrm{C}\right)$ and time $(\mathrm{h})$ at sucrose concentration of $70 \%$; (D) Fat content as a function of $\mathrm{T}\left({ }^{\circ} \mathrm{C}\right)$ and time $(\mathrm{h})$ at sucrose concentration of $70 \%$

\subsection{Weight Reduction (WR)}

For $W R$, the linear terms of sucrose concentration and temperature were found to be significant variables (Table 3), as well as the interaction between sucrose concentration and time. The $\mathrm{R}^{2}$, adj- $R^{2}$ and $p$-value for the lack of fit of the predicted model were $0.885,0.781$ and 0.589 , respectively, suggesting that the fitted model predicted well the experimental data. The recalculated model with only the significant terms is the following:

$W R=0.0145+0.0560 X_{1}-0.0178 X_{2}+0.0341 X_{1} X_{3}$
The response surface plot of sugar concentration and temperature on $W R$ is shown in Fig. $3 \mathrm{~A}$. The use of high temperature and high sucrose concentration would give the highest values of WR. When comparing the effect of the interaction of sugar concentration with time (Fig. $3 \mathrm{~B})$, we could conclude again that the highest $W R$ were obtained at high sucrose concentrations and contact times. Chenlo et al. (2007) when performing osmotic dehydration of chestnut using glycerol solutions also stated that the $W R$ increased with glycerol solution concentration. Moreover, our results are in agreement with previous studies performed on plums (Koocheki \& Azarpazhooh, 2010) where an increase in WR 
of the fruits is promoted by an increase of sucrose concentration and temperature. Nevertheless, at the highest sugar concentration, increasing the contact time from 2.5 to $7.5 \mathrm{~h}$ caused an increase of only $20 \%$ on $W R$. On the other hand, at the lowest sucrose concentration (60\%), an increase of time did not cause an increase on WR. Furthermore, in some runs (ex. 2, 9, 10, 13, 14 and 18 ), negative $W R$ values were observed due to the occurrence of a case-hardening effect that may induce some rigidity of the external cell layers and form a barrier to sucrose transfer, as suggested by Lee, Tham, and Wong (2014).

\subsection{Solids Gain ( $S G)$}

Solids gain is an important factor to consider in $\mathrm{OD}$, since it is intended to be the minimum as possible. Nevertheless, solids gain should be enough for preservation but not so high to induce changes of sensorial and nutritional properties. Only the model's linear terms were significant, and the lack of fit of the model was not significant $(p=0.260)$. The $\mathrm{R}^{2}$ and adj- $\mathrm{R}^{2}$ were 0.882 and 0.775 , respectively, showing a good adjustment between the experimental data and the values predicted by the model (all terms). When considering only the significant terms, the model obtained was:

$$
S G=0.129+0.0288 X_{1}+0.0455 X_{2}+0.0326 X_{3}
$$

Fig. 3C represents the response surface plot, showing the role of sucrose concentration and temperature on $S G$. Generally, increasing temperature always favored the $S G$ increase. At high temperatures, the effect of sugar concentration was almost negligible. Thus, the lowest $S G$ would be obtained at low sucrose concentrations and temperature.

Considering the sucrose concentration and time (Fig. 3D), the lowest $S G$ was obtained when applying low concentrations of sucrose and contact times, in line with observations by Chenlo et al. (2006a) for osmotic dehydration of whole chestnuts using glucose solutions. Nevertheless, even when high sucrose concentrations and times were used, $S G$ was always lower than 0.25. These results were in agreement with Koocheki and Azarpazhooh (2010), and Uddin,
Ainsworth, and Ibanoglu (2004), who also observed an increase in $S G$ of plums and carrots when temperature, time and sucrose concentration increased during osmotic dehydration. This could be attributed to the increased mass transfer of sugar molecules due to possible membrane swelling/plasticizing effect, enhanced by the effect of temperature and contact time, which might increase cell membrane permeability to sucrose molecules (Lazarides, Gekas, \& Mavroudis, 1997).

\subsection{Water Loss $(W L)$}

Beyond the $S G$, another main mass flux that is taking place is $W L$. During an OD process the water removal must be greater than solute acquisition (Chenlo et al., 2006a, 2007). A good fit between experimental and predicted values was obtained (Table 3), with a $\mathrm{R}^{2}$ of 0.872 and an $\operatorname{adj}-\mathrm{R}^{2}$ of 0.757 . The lack of fit of the model (all terms) was not significant $(p=0.094)$. In terms of $W L$, only sugar concentration and temperature (linear terms) were significant, yielding the following recalculated model:

$$
W L=0.143+0.0848 X_{1}+0.0277 X_{2}
$$

By analyzing the response surface plot (Fig. 3E), high temperatures and sugar concentrations promoted $W L$ that was equal to 0.30 . Moreover, the role of sucrose concentration was more significant than temperature, with a higher coefficient for the former. These results were in agreement with Park, Bin, Brod, and Park (2002) and Uddin et al. (2004) who also observed an increase in $W L$ with the increase in sucrose concentration. In general, $W L$ in osmotic dehydrated chestnuts was favored by increasing sugar concentration and temperature. These results were in agreement with Chenlo et al. (2006a), Cao et al. (2006), Eren and Kaymak-Ertekin (2007), Koocheki and Azarpazhooh (2010), Rodrigues and Fernandes (2007) and Uddin et al. (2004) for chestnuts, kiwifruit, potato, plums, melons and carrots, respectively. Indeed, when temperature increases the water diffusion rate might also increase (Kim, 1990) and it will promote faster $W L$ through swelling and plasticizing of the cell membrane, as well as by the better transfer characteristics 
Application of Response Surface Methodology to osmotic dehydration of chestnuts $\mid 63$
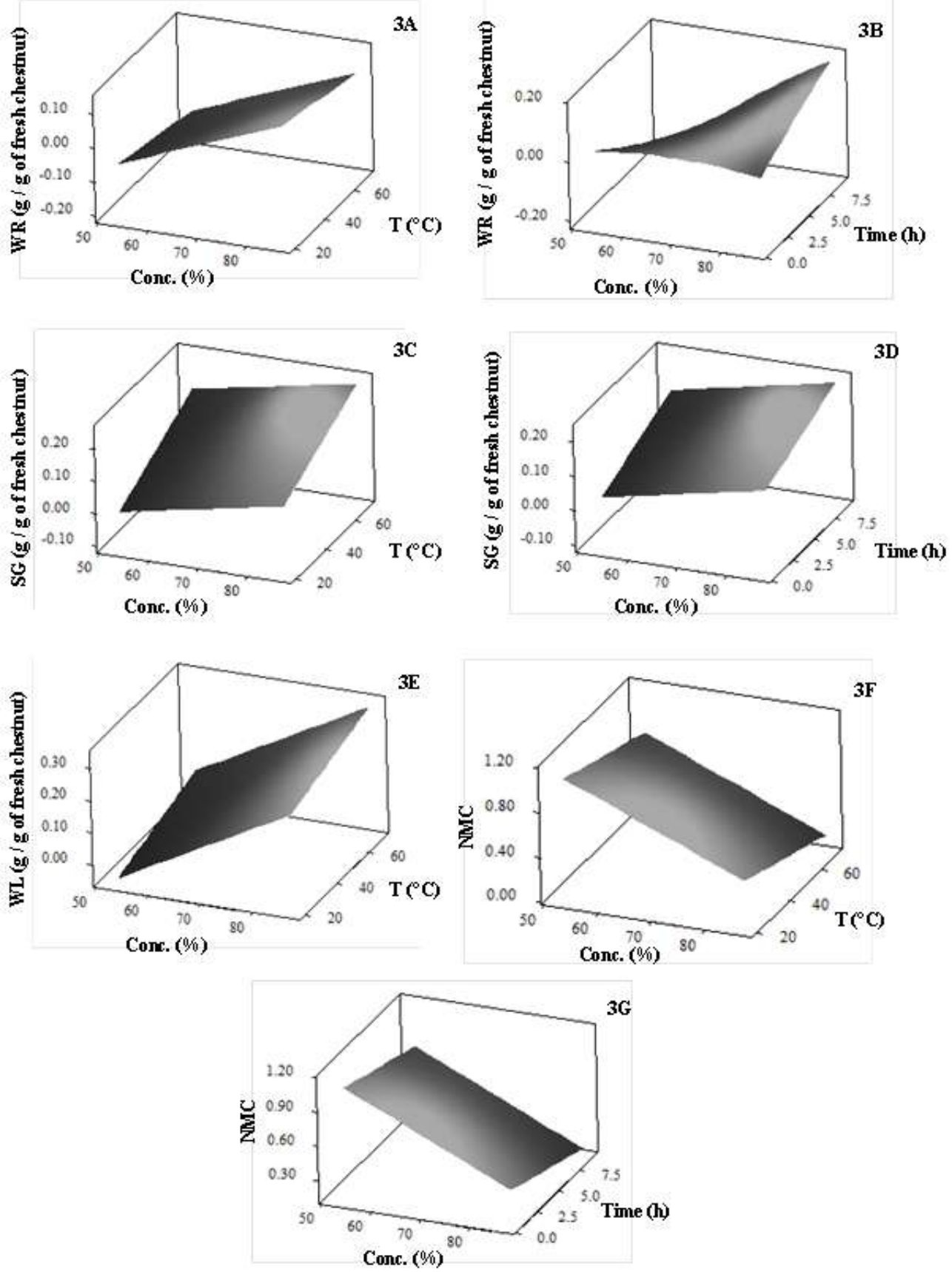

Figure 3: Response Surface plots: (A) $W R$ as a function of sucrose concentration $(\%)$ and $\mathrm{T}\left({ }^{\circ} \mathrm{C}\right)$ for a time of 5.0 hours; (B) $W R$ as a function of sucrose concentration (\%) and time (h) at $45{ }^{\circ} \mathrm{C}$; (C) $S G$ as a function of sucrose concentration $(\%)$ and $\mathrm{T}\left({ }^{\circ} \mathrm{C}\right)$ for a time of 5.0 hours; (D) $S G$ as a function of sucrose concentration (\%) and time (h) at $45{ }^{\circ} \mathrm{C} ;(\mathrm{E}) W L$ as a function of sucrose concentration $(\%)$ and $\mathrm{T}\left({ }^{\circ} \mathrm{C}\right)$ for a time of 5.0 hours; (F) $N M C$ as a function of sucrose concentration $(\%)$ and $\mathrm{T}\left({ }^{\circ} \mathrm{C}\right)$ for a time of 5.0 hours; (G) $N M C$ as a function of sucrose concentration (\%) and time (h) at $45{ }^{\circ} \mathrm{C}$ 
of the water on product surface that might be due to the lower viscosity of the osmotic medium (Contreras \& Smyrl, 1981).

\subsection{Normalized Moisture Content $(N M C)$}

In terms of $N M C$, the experimental and predicted values were similar (Table 2), were a $R^{2}$ of 0.872 , an adj- $\mathrm{R}^{2}$ of 0.756 and a non-significant lack of fit $(\mathrm{p}=0.094)$ were obtained (Table 3$)$. The experimental values varied between 0.308 and 0.987 (Table 2), which were observed when applying simultaneously high and low sugar concentrations, temperature and time, respectively. After submitting the samples to $50 \%$ sugar concentration, at $30{ }^{\circ} \mathrm{C}$ for $2.5 \mathrm{~h}$, the normalized moisture content of the samples (0.987) almost did not vary when compared to the beginning (1.0), suggesting a low water transfer of the samples to the osmotic medium and therefore ineffective drying. Again, only the linear terms were significant, with the sucrose concentration being the term with the highest negative effect. The recalculated model obtained was the following:

$N M C=0.612-0.198 X_{1}-0.0885 X_{2}-0.0741 X_{3}$

By observing Fig. 3F, the lowest $N M C$ values were obtained when applying the highest sucrose concentration and temperature. When considering the sucrose concentration with time (Fig. $3 \mathrm{G}$ ), we could observe that increasing sugar concentration caused a more pronounced decrease on $N M C$ than increasing contact time. By applying high sucrose concentrations, chestnut samples with only $30 \%$ of the moisture content of the beginning could be obtained.

Our results were in agreement with Chenlo et al. (2007) for osmotic dehydrated chestnut (whole fruits) with sucrose. These authors also reported that an increase in temperature caused lower values of $N M C$ but the intensity of the effect was higher with the most concentrated sugar solutions. Furthermore, generally our results obtained for chestnut slices by RSM were in accordance with those observed for whole fruits (chestnuts) that were osmotically dehydrated with sucrose but where this optimization methodology was not followed, namely Chenlo et al. (2007) and Moreira, Chenlo, Chaguri, and Oliveira (2007). Furthermore, our study also showed that to obtain an osmotic dehydrated product we can apply a low energy cost process due to the low temperatures that might be involved.

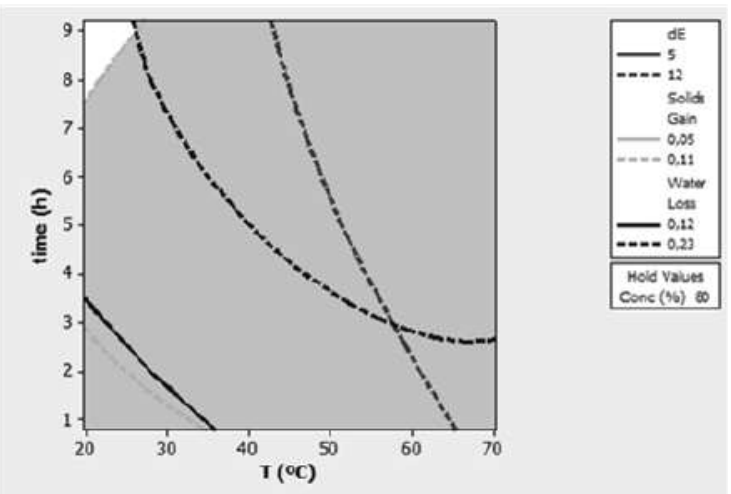

Figure 4: Combination of temperature and time to obtain $\Delta E^{*}$ between 5 and $12, S G$ between 0.05 and 0.11 , and $W L$ between 0.12 and 0.23

\subsection{Optimization of solid gain, water loss and color variation}

To evaluate the best osmotic dehydration conditions that optimized the responses of $W L, S G$ and $\Delta E^{*}$ simultaneously, an optimization study was performed using the "Response Optimizer" option of Minitab ${ }^{\circledR}$ software. Our target was to obtain simultaneously high $W L(0.12-0.23 \mathrm{~g}$ $\mathrm{g}^{-1}$ fresh matter), and low $S G\left(0.05-0.11 \mathrm{~g} \mathrm{~g}^{-1}\right.$ fresh matter) and $\Delta E^{*}$ (5-12) effects. The optimal osmotic dehydration conditions determined by the software were a sucrose concentration of $83 \%(\mathrm{w} / \mathrm{v})$, a temperature of $20{ }^{\circ} \mathrm{C}$ and a duration of 9.2 hours. Fig. 4 represents the region (white area) where the values of $\Delta E^{*}, S G$ and $W L$ mentioned above were obtained simultaneously. When the optimal conditions were applied, a $\Delta E^{*}$ equal to 7.53 , a $S G$ of $0.095 \mathrm{~g} \mathrm{~g}^{-1}$ of fresh matter and a $W L$ of $0.23 \mathrm{~g} \mathrm{~g}^{-1}$ of fresh matter were obtained, showing that these results were within the previously defined ranges. Our results for chestnut slices were in accordance with Chenlo et al. (2006a), Chenlo et al. (2007) that 
obtained the best results at low temperatures and high concentrations of the osmotic media when performing osmotic dehydration of whole fruits in glucose and sucrose solutions, respectively, and when studying osmotic dehydration kinetics without using any optimization software.

\section{Conclusions}

The optimal process parameters for the osmotic dehydration of chestnuts slices in sucrose solutions were determined by applying RSM. The developed models showed good correlation with the experimental data at $95 \%$ confidence level. The optimal osmotic dehydration conditions were $83 \%$ sucrose $(\mathrm{w} / \mathrm{v}), 20{ }^{\circ} \mathrm{C}$ and 9.2 hours to achieve maximum $W L$ and lower $S G$ and $\Delta E^{*}$. These results indicated that this process may be applied by the industry without high energy requirements and costs while not changing significantly the color of this nut, which is a characteristic valued by consumers.

\section{Acknowledgements}

Teresa Delgado acknowledges the Fundação para a Ciência e Tecnologia (FCT) for the financial support through the $\mathrm{PhD}$ grant-SFRH/BD/82285/2011, CIMO through the PEst-OE/AGR/UI0690/2014 Project and REQUIMTE through the UID/QUI/50006/2013 and NORTE-07-0124-FEDER-000069 projects, as well as POCTEP - Programa de Cooperação Transfronteiriça Espanha - Portugal through the RED/AGROTEC - Experimentation network and transfer for development of agricultural and agro industrial sectors between Spain and Portugal Project.

\section{References}

Ajandouz, E. H., Desseaux, V., Tazi, S., \& Puigserver, A. (2008). Effects of temperature and $\mathrm{pH}$ on the kinetics of caramelisation, protein cross-linking and Maillard reactions in aqueous model systems. Food Chemistry, 107(3), 1244-1252. doi:10. 1016/j.foodchem.2007.09.062
Andrés-Bello, A., Barreto-Palacios, V., GarcíaSegovia, P., Mir-Bel, J., \& MartínezMonzó, J. (2013). Effect of pH on color and texture of food products. Food Engineering Reviews, 5(3), 158-170. doi:10.1007/ s12393-013-9067-2

Anjum, M. F., Tasadduq, I., \& AlSultan, K. (1997). Response surface methodology: a neural network approach. European Journal of Operational Research, 101(1), 65-73. doi:10.1016/S0377-2217(96)00232-9

Appel, L. J., Angell, S. Y., Cobb, L. K., Limper, H. M., Nelson, D. E., Samet, J. M., \& Brownson, R. C. (2012). Population-wide sodium reduction: the bumpy road from evidence to policy. Annals of Epidemiology, 22 (6), 417-425. doi:10.1016/j.annepidem. 2012.04.003

Association of Official Analytical Chemists. (1995). Official Methods of Analysis, 16th ed. Arlington, VA: Association of Official Analytical Chemists.

Atares, L., Gallagher, M. J. S., \& Oliveira, F. A. R. (2011). Process conditions effect on the quality of banana osmotically dehydrated. Journal of Food Engineering, 103(4), 401-408. doi:10.1016/j.jfoodeng. 2010.11.010

Azarpazhooh, E. \& Ramaswamy, H. S. (2012). Modeling and optimization of microwave osmotic dehydration of apple cylinders under continuous-flow spray mode processing conditions. Food and Bioprocess Technology, 5(5), 1486-1501. doi:10.1007/s11947010-0471-9

Cao, H., Zhang, M., Mujumdar, A., Du, W. H., \& Sun, J. C. (2006). Optimization of osmotic dehydration of kiwifruit. Drying Technology, 24(1), 89-94. doi:10.1080/ 07373930500538741

Cecchini, M., Contini, M., Massantini, R., Monarca, D., \& Moscetti, R. (2011). Effects of controlled atmospheres and low temperature on storability of chestnuts manually and mechanically harvested. Postharvest Biology and Technology, 61(2-3), 131136. doi:10.1016/j.postharvbio.2011.03.001

Changrue, V., Orsat, V., Raghavan, G. S. V., \& Lyew, D. (2008). Effect of osmotic dehydration on the dielectric properties of car- 
rots and strawberries. Journal of Food Engineering, 88(2), 280-286. doi:10.1016/j . jfoodeng.2008.02.012

Chenlo, F., Moreira, R., Fernández-Herrero, C., \& Vázquez, G. (2006a). Experimental results and modeling of the osmotic dehydration kinetics of chestnut with glucose solutions. Journal of Food Engineering, 74 (3), 324-334. doi:10.1016/j.jfoodeng.2005.03. 002

Chenlo, F., Moreira, R., Fernández-Herrero, C., \& Vázquez, G. (2006b). Mass transfer during osmotic dehydration of chestnut using sodium chloride solutions. Journal of Food Engineering, 73(2), 164-173. doi:10.1016/ j.jfoodeng.2005.01.017

Chenlo, F., Moreira, R., Fernández-Herrero, C., \& Vázquez, G. (2007). Osmotic dehydration of chestnut with sucrose: mass transfer processes and global kinetics modelling. Journal of Food Engineering, 78(3), 765774. doi:10.1016/j.jfoodeng.2005.11.017

Contreras, J. E. \& Smyrl, T. G. (1981). An evaluation of osmotic concentration of apple rings using corn syrup solids solutions. Canadian Institute of Food Science and Technology Journal-journal De L Institut Canadien De Science Et Technologie Alimentaires, 14(4), 310-314.

Delgado, T., Pereira, J. A., Baptista, P., Casal, S., \& Ramalhosa, E. (2014). Shell's influence on drying kinetics, color and volumetric shrinkage of Castanea sativa Mill. fruits. Food Research International, 55, 426-435. doi:10.1016/j.foodres.2013.11.043

Derossi, A., Severini, C., Del Mastro, A., \& De Pilli, T. (2015). Study and optimization of osmotic dehydration of cherry tomatoes in complex solution by response surface methodology and desirability approach. LWT-Food Science and Technology, 60(2, 1), 641-648. doi:10.1016/j.lwt.2014.10.056

Eren, I. \& Kaymak-Ertekin, F. (2007). Optimization of osmotic dehydration of potato using response surface methodology. Journal of Food Engineering, 79(1), 344-352. doi:10. 1016/j.jfoodeng.2006.01.069

Food and Agriculture Organization of the United Nations. (2014). FAOSTAT. Retrieved from http://faostat.fao.org
Instituto Nacional de Estatística. (2014). Dados estatísticos. Retrieved from www.ine.pt

Kaymak-Ertekin, F. \& Sultanoglu, M. (2000). Modelling of mass transfer during osmotic dehydration of apples. Journal of Food Engineering, 46(4), 243-250. doi:10.1016/ S0260-8774(00)00084-4

Kim, M. H. (1990). Osmotic concentration of apples and its effect on browning reaction during air dehydration. Journal of the Korean Society of Food Science and Nutrition, $19(2), 121-126$.

Koocheki, A. \& Azarpazhooh, E. (2010). Evaluation of mass exchange during osmotic dehydration of plum using response surface methodology. International Journal of Food Properties, 13(1), 155-166. doi:10 . 1080/10942910802256172

Lazarides, H. N., Gekas, V., \& Mavroudis, N. (1997). Apparent mass diffusivities in fruit and vegetable tissues undergoing osmotic processing. Journal of Food Engineering, 31(3), 315-324. doi:10 . 1016 / S0260 8774(96)00084-2

Lee, J.-S., Tham, H. J., \& Wong, C. S. (2014). Osmotic dehydration of Kappaphycus alvarezii. Journal of Applied Phycology, 26 (2), 1063-1070. doi:10.1007/s10811-0130182-5

Lerici, C. R., Pinnavaia, G., Rosa, M. D., \& Bartolucci, L. (1985). Osmotic dehydration of fruit - influence of osmotic agents on drying behavior and product quality. Journal of Food Science, 50(5), 1217-1219. doi:10. 1111/j.1365-2621.1985.tb10445.x

Moreira, R., Chenlo, F., Chaguri, L., \& Fernandes, C. (2008). Water absorption, texture, and color kinetics of air-dried chestnuts during rehydration. Journal of Food Engineering, 86(4), 584-594. doi:10.1016/ j.jfoodeng.2007.11.012

Moreira, R., Chenlo, F., Chaguri, L., \& Oliveira, H. (2007). Drying of chestnuts (Castanea sativa Mill.) after osmotic dehydration with sucrose and glucose solutions. Drying Technology, 25(11), 1837-1845. doi:10. 1080/07373930701677686

Moreira, R., Chenlo, F., Chaguri, L., \& Vazquez, G. (2011). Air drying and colour characteristics of chestnuts pre-submitted to os- 
Application of Response Surface Methodology to osmotic dehydration of chestnuts $\mid 67$

motic dehydration with sodium chloride. Food and Bioproducts Processing, 89(C2), 109-115. doi:10.1016/j.fbp.2010.03.013

Moreira, R., Chenlo, F., Torres, M. D., \& Vázquez, G. (2007). Effect of stirring in the osmotic dehydration of chestnut using glycerol solutions. LWT-Food Science and Technology, 40(9), 1507-1514. doi:10.1016/ j.lwt.2006.11.006

Moreira, R., Chenlo, F., Chaguri, L., \& Mayor, L. (2011). Analysis of chestnut cellular tissue during osmotic dehydration, air drying, and rehydration processes. Drying Technology, 29(1), 10-18. doi:10.1080/07373937. 2010.482709

Noshad, M., Mohebbi, M., Shahidi, F., \& Mortazavi, S. A. (2012). Multi-objective optimization of osmotic-ultrasonic pretreatments and hot-air drying of quince using response surface methodology. Food and Bioprocess Technology, 5(6), 2098-2110. doi:10.1007/s11947-011-0577-8

Ozdemir, M., Ozen, B. F., Dock, L. L., \& Floros, J. D. (2008). Optimization of osmotic dehydration of diced green peppers by response surface methodology. LWT-Food Science and Technology, 41(10), 2044-2050. doi:10. 1016/j.lwt.2008.01.010

Park, K. J., Bin, A., Brod, F. P. R., \& Park, T. H. K. B. (2002). Osmotic dehydration kinetics of pear D'anjou (Pyrus communis L.) Journal of Food Engineering, 52(3), 293-298. doi:10 . 1016 / S0260 - 8774(01) 00118-2

Pereda, J. A. O., Rodríguez, M. I. C., Álvarez, L. F., Sanz, M. L. G., Minguillón, G. D. G. F., Perales, L. H., \& Cortecero, M. D. S. (2005). Tecnologia de alimentos vol. 1. Artmed: São Paulo.

Rastogi, N. K., Raghavarao, K. S. M. S., \& Niranjan, K. (1997). Mass transfer during osmotic dehydration of banana: Fickian diffusion in cylindrical configuration. Journal of Food Engineering, 31(4), 423-432. doi:10. 1016/S0260-8774(96)00086-6

Rastogi, N. K., Raghavarao, K. S. M. S., Niranjan, K., \& Knorr, D. (2002). Recent developments in osmotic dehydration: methods to enhance mass transfer. Trends in Food
Science \& Technology, 13(2), 48-59. doi:10. 1016/S0924-2244(02)00032-8

Rodrigues, S. \& Fernandes, F. A. N. (2007). Dehydration of melons in a ternary system followed by air-drying. Journal of Food Engineering, 80(2), 678-687. doi:10.1016/j. jfoodeng.2006.07.004

Sacchetti, G., Gianotti, A., \& Dalla Rosa, M. (2001). Sucrose-salt combined effects on mass transfer kinetics and product acceptability. study on apple osmotic treatments. Journal of Food Engineering, 49(2-3), 163173. doi:10.1016/S0260-8774(00)00206-5

Shi, J. \& Le Maguer, M. (2002). Osmotic dehydration of foods: mass transfer and modeling aspects. Food Reviews International, 18(4), 305-335. doi:10.1081/FRI120016208

Singh, B., Kumar, A., \& Gupta, A. K. (2007). Study of mass transfer kinetics and effective diffusivity during osmotic dehydration of carrot cubes. Journal of Food Engineering, 79(2), 471-480. doi:10.1016/j. jfoodeng.2006.01.074

Tonon, R. V., Baroni, A. F., \& Hubinger, M. D. (2007). Osmotic dehydration of tomato in ternary solutions: influence of process variables on mass transfer kinetics and an evaluation of the retention of carotenoids. Journal of Food Engineering, 82(4), 509517. doi:10.1016/j.foodeng.2007.03.008

Uddin, M. B., Ainsworth, P., \& Ibanoglu, S. (2004). Evaluation of mass exchange during osmotic dehydration of carrots using response surface methodology. Journal of Food Engineering, 65(4), 473-477. doi:10. 1016/j.jfoodeng.2004.02.007

Vasconcelos, J. I. L. A., Andrade, S. A. C., Maciel, M. I. S., Guerra, N. B., \& Vasconcelos, M. A. S. (2012). Osmotic dehydration of the Indian fig (Opuntia ficus indica) with binary and ternary solutions. International Journal of Food Science and Technology, 47(11), 2359-2365. doi:10.1111/j.13652621.2012.03110.x

Yadav, B. S., Yadav, R. B., \& Jatain, M. (2012, October). Optimization of osmotic dehydration conditions of peach slices in sucrose solution using response surface methodology. Journal of Food Science and Technol- 
$68 \mid$ Delgado et al.

ogy, 49(5), 547-555. doi:10.1007/s13197-

011-0298-Z

IJFS | April 2018 | Volume 7 | pages 52-68 